\section{Function of Combs in Ectoparasites}

MaNy ectoparasitic insects are characterized by one or more regular rows of closely set, large stout spines. These rows of spines are termed combs, or ctenidia, and have evolved independently in fleas (Siphonaptera), bat flies (Nycteribiidae), bat bugs (Polyctenidae), and in the beaver beetle Platypsyllus. Hitherto there has been little evidence about their function. It has recently been shown ${ }^{1}$ that the spacing of spines in the combs of fleas bears a close relationship to the diameter of the hairs of the appropriate host. The gap between the tips of the spines is usually about 1.75 times greater than the average diameter of the host's hairs, but the gap narrows almost to zero towards their base. The same relationship occurs between the combs of Nycteribiids and the fur of their Chiropteran hosts. The general applicability of this principle among ectoparasites was confirmed by measuring the comb of Platypsyllus castoris and the fur of the beaver. The results are summarized in Fig. 1.

The precise mode of action of the combs can be understood by considering the regularity of this quantitative correspondence and by examining the behaviour of the parasite on its host. Because the free edges of the combs always tend to point posteriorly, the hairs of the host do not become trapped between the ctenidial spines during normal forward locomotion. When a flea is dragged backwards, however, its combs catch in the host's fur. This process is assisted in two ways by the host's hair structure. First, hairs are not perfectly smooth, and in many mammalian species are characterized by deep serrations and by irregularities of cross section. Irregular projections, termed nodes, are also common on the downy barbules of birds. Second, the separate strands in fur or down do not lie parallel to one another. Most mammals show a differentiation of hairs into guard and contour hairs which are long and straight, and under-fur hairs which are much more abundant, and are finer, short and often wavy. The hairs of the under-fur often cross each other repeatedly. When an ectoparasite is moved backwards therefore it is not only the irregularities on individual hairs which become trapped between the spines, but there is also a hair tangling action analogous to that which occurs when a very fine comb is drawn through untidy human hair. The resistance to backward movement can be felt distinctly by dragging a flea through the fur of its host.

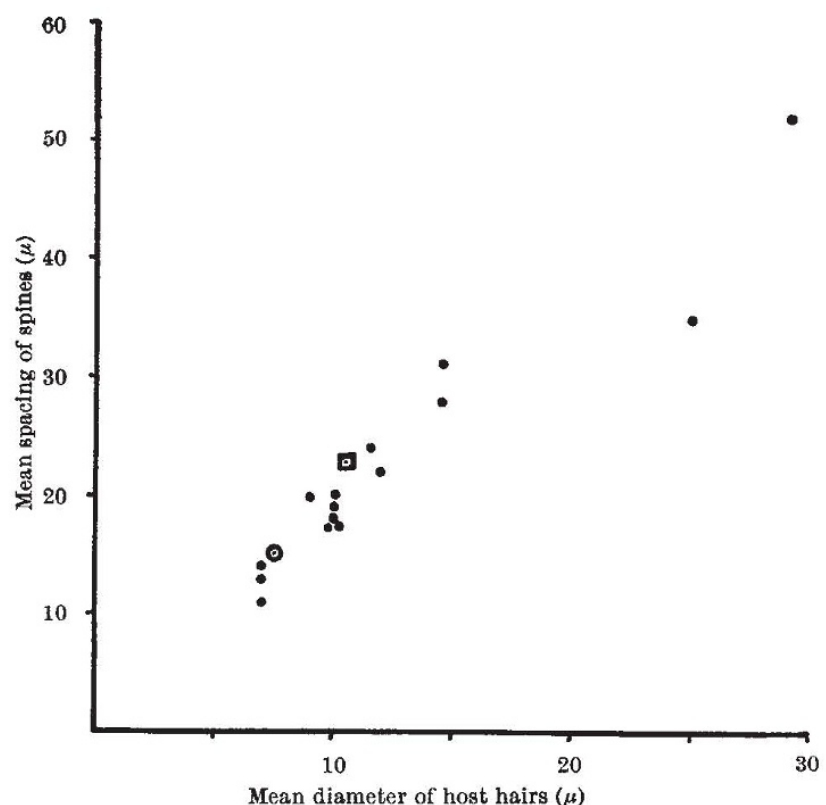

Fig. 1. Relationship between the diameter of host hairs and the spacing of ctenidial spine tips. $\odot$, Nycteribia biatticulata; $\square$, Platypsyllus castoris; $\odot$, fifteen species of flea
The survival value of the action of the combs becomes clear when we consider the situations in which ectoparasites are likely to move backwards. Fleas, at least, never do so by their own activity. Backward movement is imposed by two factors: violent movements of the host which tend to dislodge the parasite, and gripping and pulling by the host's mouth or paws. When disturbed on the host, both fleas and Nycteribiids adopt a head-down posture in the under-fur near the skin surface. It is thus their hind parts which are likely to be seized by the host. In any event, it is only backward movement which can dislodge them, and this means that the under-fur will catch in the combs. There is abundant evidence ${ }^{2-4}$ that the killing of ectoparasites by the host is a major factor limiting their populations. The mechanism of the combs can therefore be regarded as an adaptation resisting dislodgement or capture by the host. It is proposed that this is the selective advantage which underlies their convergent but independent evolution in such widely differing insect groups.

\section{A. HuMphries}

Ethology Laboratory,

Uffeulme Clinic,

Queensbridge Road,

Birmingham.

Received April 5, 1967.

${ }^{1}$ Humphries, D. A., Ent. Mon. Mag., 102, 232 (1966).

${ }^{2}$ Leeson, H. S., Parasitology, 28, 403 (1936).

${ }^{2}$ Buxton, P. A., Indian J. Med. Res., 26, 505 (1938).

‘ Buxton, P. A., Parasitology, 39, 119 (1948).

\section{Leaf Status and Photoperiodic Control of Flower Initiation in a Late Variety of Pea}

Is the absence of significant effects caused by partial defoliation in 'Greenfeast' peas, Sprent' has proposed that foliage leaves are involved in the long day flowering response of this pea variety in a qualitative rather than quantitative fashion. I agree with respect to the leaf area present at flower initiation ${ }^{2}$. I have investigated photoperiodic induction phenomena in 'Greenfeast', and suggest that the first formed foliage leaves do play an important though temporary, quantitative part in the flowering behaviour of this late variety.

I made a series of daily transfers to $8 \mathrm{~h}$ short days of plants germinated and grown in continuous light. The same light intensity $(3,500 \mathrm{ft}$.-candles) was used for both photoperiods. Artificially lit controlled environment cabinets $^{3}$ allowed transfer from a cabinet giving continuous light to one giving an $8 \mathrm{~h}$ day without changes in light intensity or growing temperature. Fig. 1 shows that a stage of development was reached after 14 days in continuous light when the node of the first flower (NF) was predetermined and was independent of the later photoperiodic regime. Only 12 days of growth in continuous light was required for about 50 per cent of the plants to initiate the first flower at the same node as plants kept continuously in the light until flower primordia were present. This irreversible commitment to flower at a predetermined node suggests that photoperiodic induction has occurred in this quantitative long day plant. Induction was achieved at least 5 days or 3 plastochron intervals before leaf initiation at the flowering node (see $\mathrm{N}$ values). Also, a preliminary histochemical investigation has shown that the flower primordium initials are not formed until the subtending leaf is morphologically discernible by dissection. Thus the possibility that the commitment to flower was a result of flower primordia already present at completion of induction can be excluded.

The number of nodes bearing unfolded leaves (Fig. I) before and at induction are particularly relevant to the role of the leaf in flowering. In general, the photoperiodic reactions involved in attainment of the induced 